\title{
Physical-Chemical Characteristics of Designer and Conventional Eggs
}

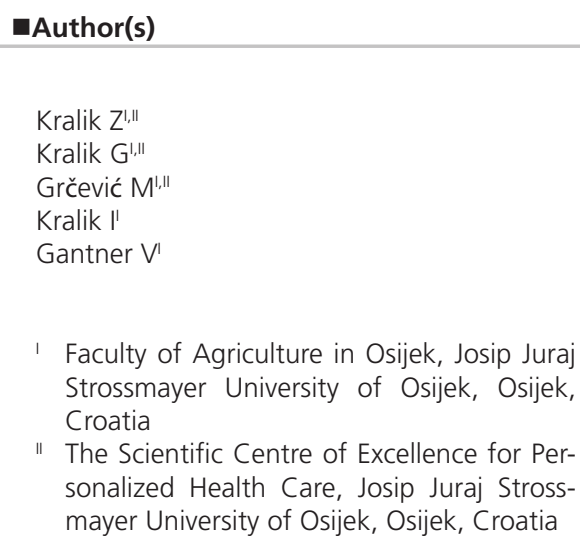

\section{Mail Address}

Corresponding author e-mail address Zlata Kralik

Josip Juraj Strossmayer University of Osijek, Faculty of Agriculture in Osijek, V. Preloga 1, 31000 Osijek, Croatia.

Tel: $\quad$ (00385)31554867

Email: zlata.kralik@pfos.hr

\section{aKeywords}

designer eggs, Haugh units, laying hens, $\mathrm{pH}$ TBARS.

\section{ABSTRACT}

The objective of this study was to compare the internal and external quality of conventional and designer eggs. In total, 120 Tetra SL laying hens were randomly allotted to two treatments ( $K$ and $P$ groups), with 12 replicates of five hens each. The control group (K) was fed a standard layer diet, producing conventional eggs, and the $\mathrm{P}$ group was fed a modified diet supplemented with $5 \%$ of an oil mixture, 0.5 $\mathrm{mg}$ organic selenium/ $\mathrm{kg}$, $200 \mathrm{mg}$ lutein $/ \mathrm{kg}$ and $200 \mathrm{mg}$ vitamin E/ $/ \mathrm{kg}$, producing designer eggs. Treatments did not influence $(p>0.05)$ egg weight or egg component weights. Designer eggs presented higher albumen proportion and lower eggshell proportion than conventional eggs $(p<0.01)$. Relative to egg quality parameters, designer eggs presented higher HU values (83.99 vs. $80.81 ; p=0.042$ ), more intense yolk color (14.38 vs. 8.70; $p<0.01)$, and lower albumen $\mathrm{pH}$ (8.39 vs. 8.67; $p=0.007)$. Feeding treatments and duration of egg storage did not significantly influence egg yolk lipid oxidation ( $p>0.05$ ).

\section{INTRODUCTION}

Eggs is an inexpensive food item and frequently used in human nutrition. They are rich in high-quality proteins, as well as in vitamins and trace minerals (Sparks, 2006). Internal and external egg quality is influenced by various factors, such as production system (Ozbey \& Esen, 2007; Yenice et al., 2016), size and type of batteries (Leenestra et al., 2014; Meng et al., 2014), feeding management and feed composition (Imran et al., 2015). By using modified feeds, designer eggs containing one or more functional ingredients, can be produced (Surai \& Sparks, 2001; Shahriar et al., 2008; Singh et al., 2012).

The aim of this study was to verify the hypothesis that the internal and external quality of designer eggs, enriched with omega-3 fatty acids, selenium, vitamin E and lutein, was similar to that of conventional eggs. In order to verify the hypothesis, the physical-chemical properties of the egg yolk, albumen and eggshell were evaluated.

\section{MATERIALS AND METHODS}

\section{Experimental design}

In this study, 120 Tetra SL hybrid laying hens, with 31 weeks of age at the beginning of the experiment were evaluated for five weeks. Birds were randomly distributed in two treatment groups: control ( $\mathrm{K}$ - conventional eggs) and experimental ( $P$ - designer eggs) groups, allotted to six cages (replicates) with five hens each, totaling 60 laying hens per group.

The diets were specially formulated and manufactured for this experiment. The ingredients and analyzed chemical composition of the 
diets are shown in the Table 1. A standard-composition diet was fed to the control group, while the diet fed to the experimental group was supplemented with 5\% oil mixture (fish oil, linseed oil, rapeseed oil, soybean oil), $0.5 \mathrm{mg} / \mathrm{kg}$ organic selenium, $200 \mathrm{mg} / \mathrm{kg}$ lutein, and $200 \mathrm{mg} / \mathrm{kg}$ vitamin $\mathrm{E}$.

All birds were housed in the same facility, which microclimatic conditions were controlled to match the requirements of laying hens. Cages were equipped with automatic feeders and drinkers.

Eggs were manually collected daily. Egg quality parameters were evaluated on fresh eggs (one day after lay). Eggs were stored in a refrigerator at +4 ${ }^{\circ} \mathrm{C}$ for 28 days after lay to determine lipid oxidation (TBARS values).

\section{Determination of external and internal egg quality}

The external and internal quality of 60 eggs of the $\mathrm{L}$ class (eggs weighing 63-73 g) was evaluated. The external egg quality parameters analyzed in this study were: egg weight, egg shape index, eggshell strength and thickness, and eggshell weight. The following internal egg quality parameters were evaluated: albumen and yolk weights, yolk color, albumen height, Haugh units (HU), and albumen and yolk pH. Moreover, proportions of main egg components (albumen, yolk, and eggshell) were calculated.

Eggs and their main components were weighed on a digital scale (model PB 1502-S, Mettler Toledo, USA). Eggshell strength was measured using an automatic device (Eggshell Force Gauge Model-II, Robotmation Co., LTD, Japan). Eggshell thickness was measured using an electronic micrometer with a precision of $0.001 \mathrm{~mm}$ in the eggshell equator.

Egg shape index was calculated according to the following equation: egg shape index (\%) = egg width/ egg length*100 (Panda, 1996). Yolk color, HU, and albumen height were determined using an automatic device (Egg Multi-Tester EMT-5200, Robotmation Co., LTD, Japan). Haugh unit (Haugh, 1937) was calculated using the following formula:

$$
\mathrm{HU}=100 \log _{10}\left(\mathrm{H}-1.7 \mathrm{~W}^{0.37}+7.57\right)
$$

where $\mathrm{H}=$ height of the albumen $(\mathrm{mm})$ and $\mathrm{W}=$ weight of egg (g)

\section{Lipid oxidation}

The oxidation of egg yolk lipids was determined in fresh eggs and in eggs stored for 28 days in a refrigerator at $+4^{\circ} \mathrm{C}$, as follows: $4 \mathrm{~g}$ of yolk was weighed in a test tube, and then $12 \mathrm{~mL}$ of $10 \%$ trichloroacetic acid were
Table 1 - Ingredients and analyzed chemical composition of the experimental diets.

\begin{tabular}{|c|c|c|}
\hline Ingredient, $\%$ & Standard diet (K) & Modified diet (P) \\
\hline Corn & 40.81 & 46.22 \\
\hline Soybean meal & 18.50 & 21.66 \\
\hline Toasted soybean & 8.30 & 4.06 \\
\hline Triticale & 15.00 & - \\
\hline Sunflower meal & 1.65 & 5.93 \\
\hline Alfalfa & 1.00 & 2.50 \\
\hline Livestock yeast & 0.50 & 1.00 \\
\hline Limestone & 9.36 & 10.31 \\
\hline Monocalcium phosphate & 1.56 & 1.50 \\
\hline Salt for animals & 0.32 & 0.64 \\
\hline Synthetic methionine & 0.24 & 0.16 \\
\hline Vitamin E & - & 0.04 \\
\hline Selenium & - & 0.05 \\
\hline Lutein & - & 0.10 \\
\hline Sunflower oil & 2.26 & - \\
\hline Oil mixture ${ }^{1}$ & - & 5.00 \\
\hline Premix $x^{2,3}$ & 0.50 & 0.50 \\
\hline Total & 100.00 & 100.00 \\
\hline \multicolumn{3}{|c|}{ Analyzed chemical composition $(\mathrm{g} / \mathrm{kg})^{4}$} \\
\hline Moisture & 87 & 82 \\
\hline Crude protein & 190 & 203 \\
\hline Crude fiber & 40 & 52 \\
\hline Ash & 139 & 170 \\
\hline Fat & 52 & 69 \\
\hline $\mathrm{Ca}$ & 41 & 50 \\
\hline
\end{tabular}

'The diet was supplemented with $5 \%$ oil $(0.75 \%$ fish oil, $1 \%$ linseed oil, $2.00 \%$ rapeseed oil, $1.25 \%$ soybean oil)

2Premix diet $\mathrm{K}$, content per $\mathrm{kg}$ : vitamin $\mathrm{A} 200000 \mathrm{UI}$, vitamin $\mathrm{D}_{3} 500000 \mathrm{UI}$, vitamin E $10000 \mathrm{mg}$, vitamin $K_{3} 600 \mathrm{mg}$, vitamin $B_{1} 400 \mathrm{mg}$, vitamin $B_{2} 1000 \mathrm{mg}$, vitamin $B_{6}$ $1000 \mathrm{mg}$, vitamin $B_{12} 3000 \mu \mathrm{g}$, vitamin C $4000 \mathrm{mg}$, vitamin H $12 \mathrm{mg}$, vitamin $B_{3} 8000$ $\mathrm{mg}$, vitamin $B_{5} 2400 \mathrm{mg}$, vitamin $B_{9} 150 \mathrm{mg}$, vitamin $B_{4} 100000 \mathrm{mg}$, iodine $200 \mathrm{mg}$, manganese $18000 \mathrm{mg}$, zinc $14000 \mathrm{mg}$, cobalt $30 \mathrm{mg}$, iron $12000 \mathrm{mg}$, copper 1600 mg, selenium inorganic 50 mg, calcium $238 \mathrm{~g}$, phytase $100000 \mathrm{FYT}$, canthaxanthin $500 \mathrm{mg}$, beta-apo-beta-carotenoic acid $300 \mathrm{mg}$, antioxidant (butylhydroxytoluene) $20000 \mathrm{mg}$

3Premix diet $\mathrm{P}$, content per $\mathrm{kg}$ : vitamin $\mathrm{A} 200000 \mathrm{UI}$, vitamin $\mathrm{D}_{3} 500000 \mathrm{UI}$, vitamin $\mathrm{E}$ $20000 \mathrm{mg}$, vitamin $\mathrm{K}_{3} 400 \mathrm{mg}$, vitamin $\mathrm{B}_{1} 420 \mathrm{mg}$, vitamin $\mathrm{B}_{2} 900 \mathrm{mg}$, vitamin $\mathrm{B}_{6} 540$ $\mathrm{mg}$, vitamin $B_{12} 2300 \mathrm{mg}, B_{9} 170 \mathrm{mg}$, Pantothenic acid $1400 \mathrm{mg}, B_{3} 5000 \mathrm{mg}$, vitamin H $17000 \mu \mathrm{g}$, vitamin $B_{4} 80000 \mathrm{mg}$, vitamin C $4500 \mathrm{mg}$, iodine $180 \mathrm{mg}$, manganese $14000 \mathrm{mg}$, zinc $12500 \mathrm{mg}$, iron $6000 \mathrm{mg}$, copper $1000 \mathrm{mg}$, selenium organic $50 \mathrm{mg}$, BHT $3400 \mathrm{mg}$, propyl gallate $1400 \mathrm{mg}$, canthaxanthin $600 \mathrm{mg}$, beta-apo-8'Carotine-acid-Ethylester $200 \mathrm{mg}$

${ }^{4}$ Referential methods applied in the chemical analysis of the feed: HRN ISO 6496:200; HRN EN ISO 5983-2:2010; HRN EN ISO 6865:2001, Modified according to instructions of FOSS Fiber Cap manual; HRN ISO 5984:2004; HRN ISO 6492:2001, Modified according to instructions of extraction system ANKOM XT15; RU-5.4.2-11 (internal method)

added. The mixture was homogenized and centrifuged for 10 minutes at $10000 \mathrm{rpm}$ and at $4^{\circ} \mathrm{C}$. After centrifugation, $2.5 \mathrm{~mL}$ of supernatant was collected and mixed with $1.5 \mathrm{~mL}$ of thiobarbituric acid solution at $\mathrm{pH}$ 2.5. The test tubes were closed and immersed into water bath for 30 minutes at $90^{\circ} \mathrm{C}$. After cooling, $1 \mathrm{~mL}$ of distilled water was added, and the mixture was centrifuged for 5 minutes at $6000 \mathrm{rpm}$ and at $4^{\circ} \mathrm{C}$. The content of colored product that occurred as a reaction 
of products of lipid peroxidation with thiobarbituric acid was measured in a spectrophotometer at $534 \mathrm{~nm}$. The obtained values were compared with standard curve prepared using standard malondialdehyde (MDA) tetrabutylammonium salt (Sigma-Aldrich, Switzerland), and expressed as $\mu \mathrm{g}$ MDA/g of yolk. Lipid oxidation was determined in 20 fresh and 20 stored eggs, totaling 40 eggs.

\section{Yolk fatty acid profile}

Fatty acid profile was determined in 6 yolks per experimental group, totaling 12 egg yolks. Yolk samples $(1 \mathrm{~g})$ were homogenized, and fat was extracted using the method of Folch et al. (1957). All solvents used were ultrapure grade (Sigma-Aldrich, Schnelldorf, Germany). A volume of $100 \mathrm{mg} / \mathrm{L}$ butylated hydroxytoluene was added to the extraction solution (chloroform/methanol $2 / 1 \mathrm{vol} / \mathrm{vol}$ ) as antioxidant. Fatty acids (FA) were then transmethylated by the base-catalyzed sodiummethoxide method of Christie (1982). Gas liquid chromatography was performed on a Shimadzu 2010 apparatus (Kyoto, Japan), equipped with a SP-2380 (Supelco, USA) type capillary column (30 m x $0.25 \mathrm{~mm}$ internal diameter, $0.20 \mu \mathrm{m}$ film) and flame ionization detector. Characteristic operating conditions were: injector temperature of $270{ }^{\circ} \mathrm{C}$, detector temperature of $300^{\circ} \mathrm{C}$, and helium flow of $28 \mathrm{~cm} / \mathrm{sec}$. The following oven temperatures were applied: from 80 to $205^{\circ} \mathrm{C}$ at $2.5^{\circ} \mathrm{C} / \mathrm{min}$, and $5 \mathrm{~min}$ at $205^{\circ} \mathrm{C}$; and from 205 to $250{ }^{\circ} \mathrm{C}$ at $10^{\circ} \mathrm{C} / \mathrm{min}$ and $5 \mathrm{~min}$ at $250^{\circ} \mathrm{C}$. In order to identify individual FA in the chromatogram, a FA standard mixture (Supelco 37 Component FAME Mix, CRM 47885) was used. The contents of saturated fatty acids (SFA), mono-unsaturated fatty acids (MUFA), as well as $n-6$ and $n-3$ polyunsaturated fatty acids (PUFA) are expressed as a percentage relative to total fatty acid content in the yolk lipids.

\section{Egg selenium content}

Egg Se content was determined in 10 yolks and 10 albumens per group, totaling 40 samples (20 yolks and 20 albumens). Laboratory equipment and glassware used for the analysis were immersed in a $10 \%$ solution of $\mathrm{HNO}_{3}$ for 24 hours.

Samples weighing $1 \mathrm{~g}$ were analyzed. Each sample was transferred to a Teflon cuvette for destruction, and $8 \mathrm{~mL} \mathrm{HNO}_{3}$ and $4 \mathrm{~mL} \mathrm{H}_{2} \mathrm{O}_{2}$ were added. After 15 minutes, cuvettes were closed and heated in a microwave oven (CEM, model Mars 5). After digestion for $25 \mathrm{~min}$, the content of cuvette was transferred to a $50-\mathrm{mL}$ flask, and the volume of the flask was completed with distilled water. Then, $20 \mathrm{~mL}$ of the sample was removed from the flask and transferred to another $50-\mathrm{mL}$ flask, and $20 \mathrm{~mL}$ of $36 \% \mathrm{HCl}$ were added. The prepared samples were placed in a dryer for one hour at $90^{\circ} \mathrm{C}$. After drying, the volume of the flask was completed with distilled water. When the samples reached room temperature, selenium content was read in a spectrometer (Perkin Elmer Optima 2100 DV0), according to Davidowski (1993).

\section{Yolk vitamin E content}

Vitamin E content was chemically analyzed in 5 yolks per experimental group, totaling 10 yolks. Firstly, $5 \mathrm{~g}$ of yolk were weighed and placed in a 50$\mathrm{mL}$ Erlenmeyer flask, after which $15 \mathrm{~mL}$ of methanol were added. The mixture remained for 16 hours at room temperature in the dark, and then decanted from the Erlenmeyer flask into $50-\mathrm{mL}$ glass recipient and allowed to precipitate. The supernatant was removed, and filtrated through a $0.45-\mu \mathrm{m}$ PTFE microfilter into an 1-mL HPLC vial. The prepared sample was then analyzed by liquid chromatography (HPLC system Agilent Technologies 1200 Series with DAD detector). The specific conditions applied were: column - Agilent, Zorbax C18 (2.1x100), $1.8 \mu \mathrm{m}$; $290 \mathrm{~nm}$ wavelength (UV area); mobile phase-100\% methanol (HPLC cleanliness); tocopherol retention time of $2.707 \mathrm{~min}$.

\section{Yolk lutein content}

Yolk lutein content was determined in 20 yolks (10 yolks per group). The method of Leeson \& Caston (2004) was applied as follows: $0.5 \mathrm{~g}$ of yolk were weighed, and poured into a test tube, to which $5 \mathrm{~mL}$ acetone were added. The solution was strongly mixed in a vortex mixer for $30 \mathrm{~s}$. Samples were left in the dark for $1 \mathrm{~h}$, filtrated through $0.45-\mu \mathrm{m}$ membrane filter, and then $1 \mathrm{~mL}$ of acetone extract was transferred to HPLC vial to evaporate slowly by heating in water bath at $40^{\circ} \mathrm{C}$. The remnant was melted by adding $1 \mathrm{~mL}$ of hexane/ethyl-acetate solution $(65: 35, \mathrm{v} / \mathrm{v})$ and mixed on a vortex. Lutein content was determined by passing the prepared samples through a RESTEK Viva C18 column ( $5 \mu \mathrm{m}, 250 \times 4.6 \mathrm{~mm}$ ). Mobile phase consisted of a mixture of methanol and tetrahydrofuran (THF) 9:1 $(\mathrm{v} / \mathrm{v})$. Flow speed was $1 \mathrm{~mL} / \mathrm{min}$, duration of analysis was 20 minutes, and measurement wavelength was $450 \mathrm{~nm}$. The volume of the injected sample was $20 \mu \mathrm{L}$. A standard lutein curve was prepared using standard lutein (ChromaDex, USA). All chemicals used were of HPLC quality. 


\section{Statistical analysis}

The effects of the dietary treatments on the weight of fresh eggs and their main components, proportions of the main egg components, external and internal quality parameters of fresh eggs, yolk fatty acid profile, and selenium, lutein, and vitamin E contents were analyzed according to the following model:

$y_{i j k l m}=m+T_{i}+e_{i j}$

where:

$y_{i j}=$ estimated parameter

$m=$ intercept;

$T_{i}=$ fixed effect of treatment $\mathrm{i}(\mathrm{i}=\mathrm{T} 1 ; \mathrm{T} 2)$;

$e_{i j}=$ residual error.

Data were submitted to analysis of variance and means were compared by the multiple comparison test of Scheffe, at 5\% significance level, using SAS software (SAS Institute Inc., 2000).

\section{RESULTS AND DISCUSSION}

Egg weight, and egg component weights and proportions are shown in Table 2. Egg weight and the weights of the main egg components were not statistically different $(p>0.05)$ between conventional and designer eggs. However, when main egg components proportions were compared, designer eggs presented significantly lower albumen and eggshell proportions $(p<0.01)$ than conventional eggs ( $60.97 \%$ vs. $62.05 \%$, and $12.09 \%$ vs. $12.72 \%$, respectively). Yolk proportion of both evaluated groups were similar $(K=26.31 \%$ and $p=25.86 \% ; p>0.05)$.

Table 2 - Egg weight and weight and proportions of main egg components $(\bar{x})$.

\begin{tabular}{lccc}
\hline Parameter & $\begin{array}{c}\text { Conventional } \\
\text { eggs }\end{array}$ & $\begin{array}{c}\text { Designer } \\
\text { eggs }\end{array}$ & $p$ value \\
\hline Egg weight, g & 67.18 & 67.46 & 0.996 \\
Albumen weight, g & 41.13 & 41.86 & 0.086 \\
Albumen proportion, \% & $60.97^{\mathrm{B}}$ & $62.05^{\mathrm{A}}$ & 0.002 \\
Yolk weight, g & 17.75 & 17.44 & 0.299 \\
Yolk proportion, \% & 26.31 & 25.86 & 0.151 \\
Eggshell weight, g & 8.30 & 8.16 & 0.409 \\
\hline Eggshell proportion, \% & $12.72^{\mathrm{A}}$ & $12.09^{\mathrm{B}}$ & 0.008 \\
\hline
\end{tabular}

${ }^{A, B} p<0.01$

Novak \& Scheideler (2001) studied the effect of the dietary addition of flax seed on the quality of chicken eggs. The authors state that increasing levels of flaxseed in the feed reduced yolk proportion. These results are considered to be beneficial, as eggs with smaller yolks contain less cholesterol compared with those with larger yolks.
Table 3 shows the external and internal quality parameters of conventional and designer eggs. No statistically significant difference in shape index was detected between conventional and designer eggs ( $p>0.05)$. Castaldo and Maurice (1988) state high levels of dietary fat affect calcium absorption and eggshell formation. Layers fed diets with high vegetable oil inclusion presented reduced calcium absorption and eggshell thickness (Brake, 1993). Flaxseed compounds, such as phytic acid, may slow down the absorption of various minerals, including calcium, which is required for calcification of the eggshell (Ahmad, 2010). In addition, phytoestrogens present in flaxseed compete with endogenous estrogens in the metabolism, and may reduce intestinal calcium absorption (Novak and Scheideler, 2001) and vitamin D3 activation, leading to reduced eggshell quality.

Yenice et al. (2016) determined a shape index of $77.74 \%$, eggshell proportion of $12.68 \%$, eggshell strength of $2.70 \mathrm{~kg} / \mathrm{cm}^{2}$ and $\mathrm{HU}$ of 70.10 in table eggs produced by caged layers. Compared with these results, the values obtained in the conventional eggs (K group) in the present study for egg shape index and eggshell proportion are slightly lower, while HU and eggshell strength are better.

Conventional eggs presented significantly stronger eggshells $\left(3.101 \mathrm{~kg} / \mathrm{cm}^{2}\right)$ compared with designer eggs $\left(2.774 \mathrm{~kg} / \mathrm{cm}^{2} ; p=0.043\right)$. In agreement with the obtained eggshell thickness values, although not statistically significant $(p=0.090)$, conventional eggs presented thicker eggshell than designer eggs $(0.410$ $\mathrm{mm}$ vs. $0.394 \mathrm{~mm}$, respectively). Yan et al. (2014) determined $0.309-0.387 \mathrm{~mm}$ eggshell thickness and $3.618-4.850 \mathrm{~kg} / \mathrm{cm}^{2}$ eggshell strength in chicken eggs, and a medium-strong correlation of 0.319 between these two parameters $(p<0.01)$. The positive impact of eggshell thickness on eggshell strength was also observed in the present study, although the values of these two parameters are noticeably lower than those reported by Yan et al. (2014). Obe et al. (2014) determined eggshell thickness values of $0.47 \mathrm{~mm}$ in free-range layers, and of $0.38 \mathrm{~mm}$ in caged layers. Gül et al. (2012) reported numerically lower eggshell thickness and strength values in the eggs of laying hens fed diets with rapeseed oil compared with those fed a control diet ( $6 \%$ oil addition $-0.38 \mathrm{~mm}$ and 1.82 $\mathrm{kg} / \mathrm{cm}^{2}$, and control group $-0.39 \mathrm{~mm}$ and $2.17 \mathrm{~kg} / \mathrm{cm}^{2}$; $p>0.05)$. Our eggshell thickness results are consistent with these findings.

Although albumen height was numerically higher in designer eggs than in conventional eggs, the difference was not statistically significant $(7.42 \mathrm{~mm}$ 
and $6.95 \mathrm{~mm}$, respectively, $p=0.052$ ). Designer eggs had significantly higher $(p=0.042)$ Haugh unit values (83.99) than conventional eggs (80.81). Kralik et al. (2017) state that HU values range between 70.36 and 71.33, which are lower compared with the results obtained in the present study (80.81 and 83.99 for conventional and designer eggs, respectively). Oke et al. (2014) found that eggs produced in different rearing systems presented 66.86-71.41 HU, with higher values obtained in younger than in older layer flocks. Hanusova et al. (2015) point out that the internal quality of eggs depends on their freshness and, therefore, it is the best to consume eggs immediately after lay. Papas et al. (2005) show that HU significantly decreases from 88.5 in fresh eggs to 75.62 in eggs stored for 14 days. During egg storage, albumen thickness is gradually reduced due to the degradation of mucinic threads, consequently reducing HU values (Kralik et al., 2014).

The results show that the yolk color of designer eggs was significantly more intense than that of conventional eggs (14.38 and 8.70, respectively; $p<0.001)$. This large difference may be explained by the different composition of the diets, as the diet of the experimental group was supplemented with lutein, which is a pigment.

Conventional eggs presented significantly higher $(p=0.007)$ albumen $\mathrm{pH}$ values than designer eggs (8.67 and 8.39, respectively), while similar yolk $\mathrm{pH}$ values were determined in both egg groups (5.99 and 5.98; $p=0.734$ ). Scheideler et al. (2010) found that albumen $\mathrm{pH}$ of fresh eggs ranges from 7.6 to 8.5 , and increased to 9.7 after 2 weeks of storage, while yolk $\mathrm{pH}$ increased from 6.0 in fresh eggs to 6.9 in stored eggs. Kralik et al. (2015) reported that albumen and yolk $\mathrm{pH}$ depend on laying hen age, with higher values observed in younger (8.94 and 7.6, respectively) than in older hens (8.85 and 6.1, respectively). Quality and extended freshness of eggs guarantee their sale (Kralik et al., 2012).

Table 3 - Comparison of external and internal quality parameters of fresh eggs $(\bar{x})$.

\begin{tabular}{lccc}
\hline Indicator & Conventional eggs & Designer Eggs & $p$ value \\
\hline Egg shape index, \% & 75.65 & 76.12 & 0.349 \\
Eggshell strength, $\mathrm{kg} / \mathrm{cm}^{2}$ & $3.101^{\mathrm{A}}$ & $2.774^{\mathrm{B}}$ & 0.042 \\
\hline Eggshell thickness, $\mathrm{mm}$ & 0.410 & 0.394 & 0.090 \\
Albumen height, $\mathrm{mm}$ & 6.95 & 7.42 & 0.052 \\
Haugh units & $80.81^{\mathrm{B}}$ & $83.99^{\mathrm{A}}$ & 0.042 \\
Yolk color & $8.70^{\mathrm{B}}$ & $14.38^{\mathrm{A}}$ & $<0.001$ \\
Albumen $\mathrm{pH}$ & $8.67^{\mathrm{A}}$ & $8.39^{\mathrm{B}}$ & 0.007 \\
Yolk pH & 5.99 & 5.98 & 0.734 \\
\hline
\end{tabular}

A, B $p<0.05$
This study showed that yolk lipid oxidation, expressed as $\mu \mathrm{g}$ MDA $/ g$ yolk, increased during storage. In conventional eggs, the determined values were $0.605 \mu \mathrm{g} \mathrm{MDA} / \mathrm{g}$ in fresh eggs, and $0.727 \mu \mathrm{g} \mathrm{MDA} / \mathrm{g}$ in stored eggs (Figure 1), while designer eggs tended to present higher MDA values, of $0.680 \mu \mathrm{g} \mathrm{MDA} / \mathrm{g}$ of yolk in fresh eggs and $0.764 \mu \mathrm{g} M D A / g$ in stored eggs. However, these differences were not statistically significant ( $p>0.05)$.

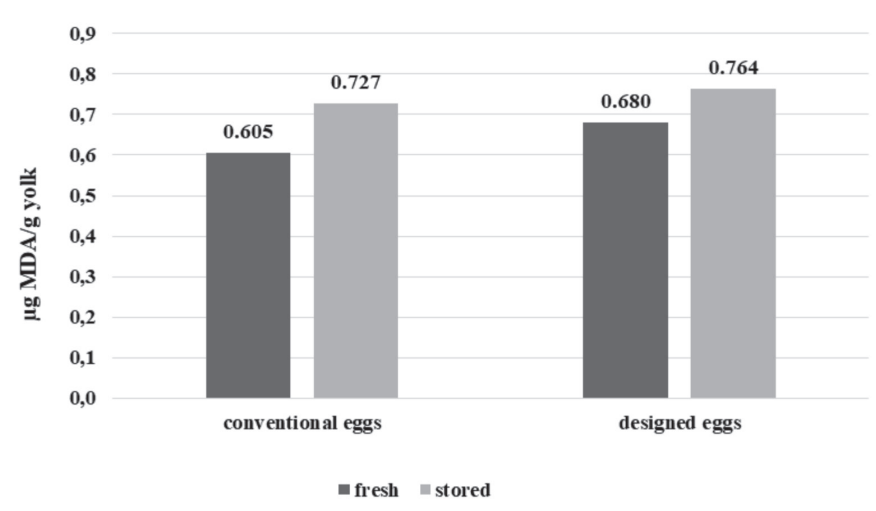

Figure 1 - Lipid oxidation in fresh and stored conventional and designer eggs

The trend of greater lipid oxidation in designer compared to conventional eggs may be due to the higher levels of unsaturated fatty acids, which are more susceptible to oxidation, in the designer eggs (Dunn-Hurrocks et al., 2011). Although designer eggs contained antioxidants, their greater lipid oxidation relative to conventional eggs may be a result of the higher dietary inclusion of oils, which contained greater levels of unsaturated fatty acids susceptible to oxidation. Dunn-Horrocks et al. (2011) reported that the inclusion of fish and linseed oils in layer diets resulted in higher TBARS values, consequently negatively influencing egg quality and shelf life. Gül et al. (2012), in study of the influence of the dietary addition of different rapeseed oil levels on the quality and omega-3 fatty acid profile of eggs, reported that increasing rapeseed oil levels increased TBARS values. Those authors obtained MDA values $(\mu \mathrm{g} / \mathrm{g})$ of 7.53 $\mu \mathrm{g} / \mathrm{g}$ and $16.68 \mu \mathrm{g} / \mathrm{g}$ in eggs stored for 21 days laid by hens fed 0 and $16 \%$ rapeseed oil, respectively. However, the research of Mohiti-Asli et al. (2008) confirmed that the supplementation of vitamin $\mathrm{E}$ and selenium in layer diets had favorable influence on lipid oxidation during storage, with eggs enriched with vitamin $\mathrm{E}$ and selenium presenting lower TBARS values than conventional eggs.

Table 4 presents n-3 PUFA, selenium, lutein, and vitamin $\mathrm{E}$ levels of designer and conventional eggs. The results show that the contents of the mentioned 
compounds were significantly higher $(p<0.001)$ in designer eggs compared with conventional eggs. According to Gajčević et al. (2009), increasing selenium levels in the feed from $0.2 \mathrm{ppm}$ to $0.4 \mathrm{ppm}$ proportionally increased Se content in the yolk from 573 to $783 \mathrm{ng} \mathrm{Se/g}$, and in albumen from 171 to $345 \mathrm{ng} \mathrm{Se/g}$. Herkel et al. (2016) reported that the dietary addition of $3 \%$ pumpkin (E1) or linseed (E2) oils increased total n-3 PUFA levels in the eggs from $1.43 \%$ (control group) to $4.72 \%$ (E1) and $6.80 \%$ (E2).

The addition of lutein in layer feed increases its content in the egg yolks, according to Leeson and Caston (2004). Those authors demonstrated that the inclusion of 375 ppm lutein to a diet based on corn and soybean meal increased egg lutein content from $0.3 \mathrm{mg}$ to $1.5 \mathrm{mg} / 60 \mathrm{~g}$ egg.

Table 4 - Levels of n-3 PUFA, selenium, lutein, and vitamin $\mathrm{E}$ in conventional and designer eggs $(\bar{x})$.

\begin{tabular}{lccc}
\hline${ }^{*}$ per $100 \mathrm{~g}$ of yolk & Conventional eggs & Designer eggs & $p$ value \\
\hline n-3 PUFA $(\mathrm{mg})$ & $366.53^{\mathrm{B}}$ & $876.62^{\mathrm{A}}$ & $<0.001$ \\
Selenium - albumen $(\mu \mathrm{g})$ & $5.3^{\mathrm{B}}$ & $14.3^{\mathrm{A}}$ & $<0.001$ \\
Selenium - yolk $(\mu \mathrm{g})$ & $38.7^{\mathrm{B}}$ & $66.2^{\mathrm{A}}$ & $<0.001$ \\
Lutein $(\mathrm{mg})$ & $1.24^{\mathrm{B}}$ & $10.49^{\mathrm{A}}$ & $<0.001$ \\
Vitamin E - yolk $(\mathrm{mg})$ & $1.25^{\mathrm{B}}$ & $1.98^{\mathrm{A}}$ & $<0.001$ \\
\hline
\end{tabular}

${ }^{A}, \mathrm{~B} p<0.05$

In a study on egg enrichment with vitamin $E$ and selenium, Gjorgovska et al. (2011) reported that the addition of vitamin E to layer diets at 100 (E1) or 230 $\mathrm{mg} / \mathrm{kg}$ of feed (E2) significantly increased yolk vitamin E content compared with the control group $(K)$, where hens were fed $30 \mathrm{mg}$ vitamin E/ $\mathrm{kg}$, obtaining values of $1.68 \mathrm{mg} /$ yolk (K), $2.90 \mathrm{mg} /$ yolk (E1) and $5.58 \mathrm{mg} / \mathrm{yolk}$ (E2). Pal et al. (2002) found that the vitamin E content of egg yolks doubled when dietary vitamin $E$ level was increased from 55 to $110 \mathrm{lU} / \mathrm{kg}$ of feed.

\section{CONCLUSIONS}

Based on the results of this study, it is concluded that the modification of layer diets for the purpose of producing eggs enriched with various nutrients (omega-3 fatty acids, selenium, vitamin E, and lutein) has no negative impact on the physical-chemical indicators of table eggs.

Moreover, in comparison with conventional eggs, designer eggs presented better egg yolk color, albumen height, and $\mathrm{HU}$ values, as well as more favorable albumen and yolk pH values. Although the enriched diet had a negative effect on eggshell strength, the other evaluated eggshell quality parameters of the designer eggs were not significantly different $(p>0.05)$ from those of the conventional eggs and were not lower than the optimal values for table eggs.

\section{ACKNOWLEDGEMENTS}

This paper is a part of the research unit "Research, Manufacturing and Medical Testing of Functional Food", within "The Scientific Centre of Excellence for Personalized Health Care", Josip Juraj Strossmayer University of Osijek, supported by the Ministry of Science and Education of the Republic of Croatia.

\section{REFERENCES}

Ahmad S. Effect of supplementing dietary sources of n-3 fatty acids and vitamin A on laying performance, egg quality, and immune response in laying hens [dissertation]. Faisalabad (PAK): University of Agriculture, Department of Poultry Science; 2010.

Brake J. Recent advances in induced molting. Poultry Science $1993 ; 72(5): 929-931$.

Castaldo D, Maurice D. Phospholipid content of the eggshell gland and its relationship to eggshell strength. Poultry Science 1988;67(3):427-433.

Christie WW. A simple procedure for rapid transmethylation of glycerolipids and cholesteryl esters. Journal of Lipid Research 1982;23:1072-1075.

Davidowski L. ICP application study number 67. São Paulo: Perkin Elmer 1993.

Dunn-Hurrocks S, Pichardo-Fuchs M, Lee J, Ruiz-Feria C, Creger C, Hyatt $D$, et al. Effect of omega-3 enriched layer rations on egg quality. International Journal of Poultry Science 2011;10(1):8-11.

Folch JM, Lees M, Sloane-Stanley GH. A simple method for the isolation and purification of total lipids from animal tissues. Journal of Biological Chemistry 1957;226(1):495-509

Gajčević Z, Kralik G, Has-Schon E, Pavić, V. Effects of organic selenium supplemented to layer diet on table egg freshness and selenium content. Italian Journal of Animal Science 2009;8(2):189-199.

Gjorgovska N, Chuleva B, Filev K. Enrichedd eggs with vitamin E and selenium. Lucrări Ştiințifice - Seria Zootehnie 2011;55:319-323.

Gül M, Yörük MA, Aksu T, Kaya A, Kaynar Ö. The effect of different levels of canola oil on performance, egg eggshell quality and fatty acid composition of laying hens. International Journal of Poultry Science 2012;11(12):769-776.

Haugh RR. The Haugh unit for measuring egg quality. United States Egg Poultry Magazine 1937;43:552-573.

Hanusova E, Hrnčár C, Hanus A, Oravcová M. Effect of breed on some parameters of egg quality in laying hens. Acta Fytotechnica et Zootechnica 2015;18(1):20-24

Herkel R, Gálik R, Arpášova H, Bíro D, Juráček M, Šimko M, et al. Fatty acid profile and nutritional composition of table eggs after supplementation by pumpkin and flaxseed oils. Acta Veterinaria Brno 2016;85(3):277283

Imran M, Anjum FM, Nadeem M, Ahmad N, Khan MK, Mustaq Z, et al. Production of Bio-omega-3 eggs through the supplementation of extruded flaxseed meal in hen diet. Lipids in Health and Disease 2015;14:126 
Kralik Z, Kralik G, Grčević M Kralik I, Gantner V
Oke OE, Ladokun AO, Onagbesan OM. Quality parameters of eggs from chickens reared in deep litter system without success grass or legume pasture. Livestock Research for Rural Development 2014;26(11):1-11.

Ozbey O, Esen F. The effects of different breeding systems on egg quality characteristics of rock partridges. Poultry Science 2007;86(4):782-785.

Pal L, Dublecz K, Husveth F, Wagner L, Bartos A, Kovacs G. Effect of dietary fats and vitamin $E$ on fatty acid composition, vitamin $A$ and $E$ content and oxidative stability of egg yolk. Archiv für Geflügelkunde 2002;66(6):251-257.

Panda PC. Shape and texture. In: Panda PC, editor. Textbook on egg and poultry technology. New Delhi: Vikas Publishing House; 1996. p.57.

Pappas AC, Acamovic T, Sparks NHC, Surai PF, Mc Devitt RM. Effects of supplementing broiler breeder diets with organic selenium and polyunsaturated fatty acids on egg quality during storage. Poultry Science 2005;84(6):865-874

SAS. User's guide: version 8.2. Cary: SAS Institute; 2000

Scheideler SE, Weber P, Monsalve D. Supplemental vitamin E and Se effects on egg production, egg quality, and egg deposition of $\alpha$-tocopherol and Se. The Journal of Aplied Poultry Research 2010;19(4):354-360.

Shahriar HA, Adl KN, Nezhad YE, Nobar RSD, Ahmadzadah A. Effect of dietary fat type and different levels of vitamin $E$ on broiler breeder performance and vitamin E levels of egg. Asian Journal of Animal and Veterinary Advances 2008;3(39):147-154.

Singh VP, Pathak V, Akhilesh KV. Modified or enriched eggs: a smart approach in egg industry: a review. American Journal of Food Technology 2012;7(5):266-277

Sparks NHC. The hen's egg - is its role in human nutrition changing? World's Poultry Science Journal 2006;62(2):308-315

Surai PF, Sparks NHC. Designer eggs: from improvement of egg composition to functional food. Trends in Food Science \& Technology 2001;12(1):716.

Novak CL, Scheideler SE. Long-term effects of feeding flaxseed-based diets. Egg production parameters, components, and eggshell quality in two strains of laying hens. Poultry Science 2001;80(10):1480-1489. 
